\title{
RELATO DE UMA EXPERIÊNCIA \\ UTILIZANDO-SE A CLARA DE OVO NA DERMATITE AMONIACAL NO CENTRO DE CONVIVÊNCIA INFANTIL DO INSTITUTO “DANTE PAZZANESE" DE CARDIOLOGIA.
}

\author{
Lindalva de Jesus da Silva * \\ Ana Maria de Mello Mesquita Confalonieri ** \\ Fabiane Soares de Amorim ***
}

\begin{abstract}
RESUMO - As autoras deste trabalho se propõem mostrar a atuação de clara de ovo nas dermatites amoniacais, em crianças que freqüentam o Centro de Convivência Infantil do Instituto "Dante Pazzanese" de Cardiologia, avaliando a eficácia de sua utilização. Para isso, apresentam 35 casos de assadura ocorridos no período de janeiro a junho de 1988, com resultados satisfatórios.
\end{abstract}

ABSTRACT - The authors of this paper aim at showing the action of the egg white on ammoniacal skin irritation on children frequenting the Day Nursery of "Dante Pazzanese" Cardiology Institute, evaluating the efficiency of its use purpose, 35 cases of roasting between January and June 1988 are presented, with satisfatory results.

\section{INTRODUÇÃO}

"Estimular, orientar e coordenar a implantação de programas e serviços de proteção à matemidade e à infância, avaliá-los e aperfeiçoá-los são atribuições da Coordenação de Proteção Materno Infantil, órgão integrado do Ministério da Saúde, que substitue o antigo Departamento Nacional da Criança ${ }^{8}$ ".

1 Motivado pelo Ano Internacional da Criança, (1979), o Governo, através do decreto de número 15.812, datada de 08 de outubro de 1980 , cria e organiza os Centros de Convivência Infantil (CCI) em unidades da Secretaria de Saúde, inicialmente com a implantação de seis (06). Esses centros são destinados a dar assistência à crianças, filhos de funcionários e servidores públicos estaduais, ficando a cargo do Fundo Social de Solidariedade do Estado de São Paulo (FUSSESP) determinar as diretrizes e bases para o funcionamento dos mesmos.

O CCI do Instituto "Dante Pazzanese" de cardiologia (IDPC) iniciou suas atividades em fevereiro de 1981, com capacidade para atender 47 crianças de ambos os sexos, na faixa etária de 0 a 48 meses, onde é dispensado atendimento integral à criança, num perfodo diário de nove horas, equivalente a jornada de trabalho de seus pais.

Considerando que os CCIs visam atender crianças sem agravos de saúde, os responsáve1s por essa assistência confrontam-se diariamente com pequenos problemas inerentes à criança sadia, estando entre os de maior freqüência a Dermatite Amoniacal (assadura).

AUGUSTO' define dermatite amoniacal, tamberm conhecida como assadura de fraldas ou dermatite de contato, como uma irritação cutânea da região perineal caracterizada p/manchas avermelhadas escamosas, decorrentes da formação de amônia pela ação bacteriana sobre a uréia. Entretanto MARCONDES ${ }^{7}$ refere que a ação irritativa não provêm dos produtos amoniacais decorrentes da decomposição da uréia urinária, já que se demonstrou serem os níveis locais de amônia idênticos em crianças com ou sem dermatite, e não são suficientes para irritar a pele. Para esse autor a dermatite amoniacal caracteriza-se por eritema e descamação discreta nas superfícies convexas das nádegas, escroto, região superior da coxa, região hipogástrica, poupando as dobras nos graus mínimos. Pode evoluir para o surgimento de vesículas, fissuras, erosões e secreções (eczematização), que se tornam amareladas com crostas melicéricas (infecção piogênica secundária). As crostas são cremosas na associação com Monilíase secundária. As erosões podem se tornar elevadas com

* Chefe do Serviço de Enfermagem do Centro de Convivência Infantil do Instituto "Dante Pazzanese". Especializada em Enfermagem Médico Cirúrgica e Administração Hospitalar

** Enfemeira do Setor de Pediatria e do Centro de Convivência Infantil. Especializada em Administração Hospitalar

*** Enfermeira - Especializada em Cardiologia - Pediatria e Puericultura 
pápulas e nódulos inflamatórios que lembram a sífilis secundária.

$\mathrm{Na}$ nossa vivência temos observado que a dermatite amoniacal, no CCI tem sido um problema para as crianças, mães e também para a instituição. Com relação às crianças, esta afecção cutânea produz irritabilidade emocional (inquietação, choro freqüente etc), atuando como porta de entrada para infecções quando há solução de continuidade. A mãe, por sua vez, torna-se mais preocupada com a dificuldade em lidar com esse problema, além do aumento de seu trabalho com as trocas de fraldas mais freqüentes, maior vigilância na lavagem das mesmas e falta de tempo disponível. LAMA$\mathrm{RE}^{5}$ ainda enfatiza ser mais um esforço para a mãe, pois a mesma tem que levantar a noite para trocar as fraldas. Para a instituição, há uma maior sobrecarga de trabalho, necessitando uma melhor distribuição dos funcionários, além dos recursos materiais utilizados (maior número de trocas, água, medicamentos tópicos etc). Há uma tendência de se deslocar uma funcionária para atender essas necessidades básicas, físicas, afetadas em detrimento das atividades psicopedagógicas, interferindo, portanto, no relacionamento individual das crianças. Pela experiência, observa-se, também, que para as funcionárias há um desgaste emocional ao presenciar o' sofrimento da criança, com quem sempre desenvolvem uma interação bastante afetiva.

Muitos autores tem abordado alguns cuidados em relação a dermatite amoniacal, entre os quais citamos: MURAHOVSCHI ${ }^{\circ}, \mathrm{WERNER}^{13}$, SAMPAIO ${ }^{10}$, MARCONDES ${ }^{7}$, AUGUSTO', WAECHTER ${ }^{12}$, LAMARE $^{5}$ e o MANUAL DO HOSPITAL GOLDEN GARDEN ${ }^{\natural}$, que enfocam, de uma maneira geral, as seguintes condutas:

- Deixar a criança sem fraldas o maior tempo possível, expondo a região perineal ao ar, luz e sol, (podendo manter uma toalha sob a criança enquanto estiver sem fraldas) nos horários em que predomina a ação'ultra violeta.

- Trocar as fraldas frequentemente, preferindo as de pano e abolindo o uso de fraldas pintadas.

- Higienizar o períneo com água morna. Usar sab:o suave somente após as evacuaçōes e evitar o uso de produtos à base de hexaclorofeno (soapex), triclorocabanilida ou pentaclorofenol).

- Quando a criança estiver de fralda, deixá-la frouxa, permitindo a circulação de ar entre ela e a pele. Se for descartável, perfurá-la para permitir a entrada do ar, ou abolir seu uso se a criança apresentar alergia ao produto.

- Não usar calças plásticas por alguns dias, especialmente durante à noite.

- Lavar as fraldas normalmente com água e sabão e enxaguá-las com solução de alvejante (cândida), ou acidificá-las com vinagre ou limāo.

- Deixar a criança em decúbito ventral diminuíndo o contato da urina com a genitália.

- Evitar o uso de pós, oleos, sabōes germicidas, detergentes e amaciantes para lavagem das fraldas, mercúrio cromo e medicações tópicas inadequadas.

- Evitar a higiene excessiva com fricção exagerada, tão prejudicial quanto a higiene precária.

Para o tratamento tópico da Dermatite Amoniacal, autores como: BRUNNER $^{2}$, LAMARE $^{5}$, MARCONDES $^{7}, \mathrm{MURAHOVSCHI}^{\ominus}$, SAMPAIO $^{10}$, SCHWARTSMANN ${ }^{11}$, WER$\mathrm{NER}^{13}$, citam como condutas mais utilizadas:

- Compressas de permaganato de patássio, nas concentrações de 1:10.000 ou 1:40.000.

- Solução de Burrow, 4 colheres de chá de solução dilứda em $200 \mathrm{ml}$ de água.

- Pomada de Lassar.

- Preparos à base de cortisona.

- Preparo de óxido de zinco $(50 \mathrm{~g})$ e óleo de oliva (180 ml).

- Violeta de genciana a $1 \%$ em solução aquosa, se associada à monilíase.

- Antibiótico e fungicidas em pomadas.

- Vitamina A e D em pomada (ad-furp), Hipoglos.

- Nistatina ou Micostaim.

- Preparado de ictiol $(1,5)$ mais óxido de zinco $(3,0)$ mais vaselina $(30,0)$, usando óleo mineral (Nujol) para retirar a pomada.

- Antibiótico sistêmico nas infecções externas.

SCHWARTSMANN ${ }^{11}$ relata que o ácido bórico é um agente de pequena e lenta atividade antimicrobiana, agindo primordialmente como bacteriostático, mesmo em soluções concentradas. Não há razão para o seu uso, qualquer que se ja a apresentação, sendo injustificável e perigosa a utilização para o tratamento da Dermatite Amoniacal. Também cita que a clorohexidina (clorex) é considerada bom agente antisséptico, ineficaz contra bactérias gram negativas e vírus. $O$ uso excessivo ou repetido pode determinar fotossensibilidade e dermatite de contato.

Pudemos confirmar isso em nossa prática diária, em que se observou a sua eficiência no primeiro dia de aplicação em casos de dermatite, surgindo irritação local ao aplicá-lo nos dias subseqüentes, com hiperemia local $e_{1}$ irritabilidade emocional. Com relação ao mercúrio cromo (Melbromino) SCHWARISMANN ${ }^{1}$ considera um agente de fraca atividade bacteriostática, de pequeno poder de penetração nos tecidos, diminuíndo sua atividade na presença de proteínas séricas e teciduais. As soluçōes aquosas contaminam-se por bactérias gram negati- 
vas, não havendo razão para seu uso antisséptico, não se definindo ainda os possíveis riscos tóxicos do uso excessivo e prolongado em crianças.

Pela nossa experiência de 6 (seis) anos como enfermeiras responsáveis pela assistência direta às crianças que freqüentam o CCI, pudemos constatar que têm ocorrido modificações constantes, no que se refere às medidas terapêuticas o utilizadas para o tratamento da Dermatite Amoniacal.

As fezes diarrécas são responsáveis por grande parte das dermatites, pois contêm grande quantidade de ácidos orgânicos, que podem queimar a pele em contato prolongado com estas, todavia as lesões desaparecem ao ser tratada a diarréia.

Além das condutas tradicionais, preconizadas pela área médica, utilizamos várias outras como: polvilho associado às mais diversas pomadas, agentes químicos como o mercúrio cromo, bleo de cozinha, maizena, entre outros.

Em dezembro de 1987, uma das funcionárias do CCI foi por nós surpreendida, utilizando clara de ovo em uma criança com dermatite amoniacal, resistente a todos os outros meios dispensados para seu tratamento. Quando abordada a respeito de tal conduta, relatou que aprendera com uma vizinha bastante idosa e que cuidava de seu filho, portador de frequiente e persistente dermatite amoniacal, fazendo uso de clara de ovo com sucesso. A funcionária foi orientada por nós para não tomar nenhuma conduta nova sem que fosse previamente estudada, discutida e fundamentada sob o ponto de vista científico. Este caso deu início à investigação para o presente estudo.

Estudando o ovo, especificamente a clara, encontramos em GUEDES 4 , a explicação para aquela conduta levantada, já que esta autora esclarece que a "clara $e$ formada de diversas camadas de substâncias albuminóides e de água, que constituem cerca de $57 \%$ do peso total do ovo. Além dessas substâncias a clara contém glucose, substâncias gordurosas, substâncias extrativas e alguns minerais. Aproximadamente $55 \%$ da clara é constituída de ambúmen espesso. O albúmen do ovo contém proteínas completas, constiturdas de todos os aminoácidos indispensáveis e em proporções adequadas. Contém algumas vitaminas do complexo B, solúveis em água, especialmente a riblofavina".

CAMPEDELLI ${ }^{3}$, já cita que existem trabalhos com a utilização da clara de ovo em lesões cutâneas provocadas por escaras.

Considerando ser a clara de ovo, de custo reduzido e fácil obtenção, está acessível a qualquer tipo de instituição e possibilita a continuidade do tratamento a nível domicialiar.

Acreditamos na sua eficácia e decidimos experimentá-la no nosso serviço.

Pretendemos, portanto, avaliar a aplicação da clara de ovo no tratamento da dermatite amoniacal em crianças que freqüentam o Centro de Convivência Infantil do Instituto "Dante Pazzanese" de Cardiologia, no período de janeiro a junho de 1988.

\section{METODOLOGIA \\ População}

Utilizou-se a clara de ovo para o tratamento dos casos de Dermatite Amoniacal ocorridos no período de janeiro a junho de 1988 .

A capacidade do CCI é de 47 crianças, que freqüentam diariamente. A população constitúu-se de 35 crianças com dermatite amoniacal, considerando-se as recidivas que ocorreram com uma mesma criança.

\section{Método de Utilização da Clara de Ovo:}

O procedimento é realizado separando-se inicialmente a clara de ovo fresco. Em seguida, separa-se a clara batendo-a até formar espuma, a fim de torná-la consistente e facilitar sua aplicação. Após o primeiro uso a clara batida é guardada em um frasco tampado e utilizada durante o dia, correspondendo a cerca de 7 horas de uso. Deve ser conservada em lugar fresco, dispensando a refrigeração, sendo desprezada ao final deste período.

Procede-se a higiene local da área lesada com água moma, secando bem e aplicando a clara batida com o auxilio de algodão. $O$ perrneo é mantido descoberto por 20 a 30 minutos, para permitir que a clara de ovo seque, formando uma película sobre a zona de dermatite. Depois as fraldas são fixadas, e assim permanecem até a próxima troca, quando se faz nova higiene local com água morna e outra aplicação da clara de ovo.

O procedimento é continuado até que desapareçam todos os sinais de dermatite ou se observe melhora total das condições cutâneas, através do exame físico diário.

Existem meios de avaliar a idade e o estado do ovo descritos por GUEDES ${ }^{4}$ e LAMARE ${ }^{5}$. No entanto, em nossa vivência diária, temos utilizado para classificá-lo como fresco a aparência opaca e áspera da casca, e que não apresente mobilidade quando o mesmo é movimentado.

\section{RESULTADOS}

Dos 36 casos acompanhados, o primeiro caso, ocorrido em dezembro de 1987 , não foi incluído no presente estudo, mas foi o que nos motivou a uma investigação mais elabcrada, necessitando de uma uniformização de condutas, como a não utilização concomitante de produtos ou medicamentos. 
Tabela 1 - Distribuição do número de casos normais, associada à duração média dos episódios de dermatite amoniacal ocorridos no Centro de Convivência Infantil do·Instituto "Dante Pazzanese" de Cardiologia,, em 1988.

\begin{tabular}{ccc}
\hline Meses & Número de casos & Duraçāo Media dos Epsódios (em dias) \\
\hline Janeiro & 03 & 3,3 \\
Fevereiro & 09 & 4,2 \\
Março & 06 & 4,0 \\
Abril & 06 & 2,0 \\
Maio & 06 & 2,3 \\
Junho & 05 & 2,0 \\
\hline Total & 35 & 3,0 \\
\hline
\end{tabular}

A tabela 1 mostra que o maior número de casos de assadura ocorreu no mês de fevereiro (09), enquanto no mês de janeiro observou-se a menor ocorrência de casos (03).

Com relação a duração dos epsódios, verificou-se que em fevereiro e março, obteve-se uma média de 4 dias, sendo que nos meses de abril e junho encontrou-se a menor duração média dos episódios (2 dias).

Dentre os 35 casos estudados, a duração média calculada foi de 3 dias.

Tabela 2 - Distribuição do número de casos de acordo com a duração da Dermatite Amoniacal, e freqüencia no Centro de Convivência Infantil do Instituto "Dante Pazzanese" de Cardiologia, de janeiro a junho de 1988.

\begin{tabular}{cccc}
\hline Duraçāo do Epsodio (em dias) & Número de Casos & \% \\
\hline 2 & 18 & 51,4 \\
& 3 & 7 & 20,0 \\
4 & 4 & 11,4 \\
5 & 2 & 5,7 \\
6 & 3 & 8,6 \\
& + de 6 & 1 & 2,9 \\
\hline Total & & 35 & 100,0 \\
\hline
\end{tabular}

Pela tabela 2, evidencia-se que, 51,4\% dos casos (18) apresentaram a duração mínima do episódio de 2 dias após a aplicação da clara de ovo, enquanto uma pequena percentagem $(2,9 \%)$, correspondendo a 1 caso, teve duração superior a 6 dias. Deve-se considerar que, neste caso, não houve colaboração por parte da mãe em seguir as orientações preconizadas ao tratamento da assadura pelo CCI.

Tabela 3 - Distribuição do número de casos em função da idade das crianças com Dermatite Amoniacal no Instituto "Dante Pazzanese" de Cardiologia, de janeiro a junho de 1988.

\begin{tabular}{ccc}
\hline & Faixa Etária (meses) & Número de Casos \\
\hline $5-7$ & 1 \\
$7-9$ & 10 \\
$9-11$ & 9 \\
$11-13$ & 8 \\
$13-15$ & 2 \\
& $15-18$ & 5 \\
\hline Total & & 35 \\
\hline
\end{tabular}

Avaliando a tabela 3, pode-se constatar que a maior incidência de assadura ocorreu em crianças na faixa etária de 7 a 11 meses (19 casos), concordando com a literatura, que mostra serem as crianças menores mais predispostas a dermatite. Observa-se que o número de casos de assadura diminuiu entre as crianças de 13 a 18 . meses. Este período coincide com a fase de educação dos esfincteres, em que as criança passa maior tempo sem fraldas, contribuindo para a diminuição das assaduras. Não consideramos ser a faixa dos 5 aos 7 meses, a de menor incidência (1) como mostra a tabela, visto que só havia uma criança com 5 meses, admitida em junho, no CCI durante o período de observação de nosso trabalho. 


\section{CONCLUSÕES}

Este trabalho originou-se do acompanhamento com observação e registro sistematizado quanto à evolução das dermatites amonicais nas crianças que freqüentam o CCI do IDPC.

Apesar do período de observação ter sido de apenas 6 meses, verificamos que todos os casos de dermatite amoniacal tratadas somente com clara de ovo, regrediram totalmente. Percebemos tamberm que, nas, recidivas, a assadura apresentou-se de forma mais leve, considerando-se ter iniciado esta aplicação desde o aparecimento dos primeiros sinais de irritação cutânea.
Pretendemos dar continuidade a este trabalho acompanhando crianças no próprio CCI, por um período de um ano, a fim de tornar mais fidedígno os resultados encontrados e de estudar o aparecimento da dermatite em função das estações do ano, bem como avaliar o uso da clara de ovo nestas épocas.

Esperamos que nosso trabalho forneça subsídios para o desenvolvimento de outras pesquisas relacionadas à utilização da clara de ovo, para que se estabeleça novas condutas de enfermagem direcionadas ao tratamento da dermatite amoniacal.

\section{REFERÊNCIAS BIBLIOGRÅFICAS}

1. AUGUS TO, M. Comunidade infantil - creche - 2 ed., Rio de Janeiro: Guanabara Koogan, 1985. p. 104.

2. BRUNNER, L.S., SUDDAR TH D.S. Tratado de enfermagem médico cirúrgica. 4. ed., Rio de Janeiro: Interamericana, 1982. p. 1105 e 1164.

3. CAMPEDELLI, M.C., GAIDZINSKI, R.R. Escara: problema na hospitalização, São Paulo: Ática, 1987. p. 64.

4. GUEDES. R. O ovo e seus aspectos. Rio de Janeiro: SIA, 1961. p. 9 - 85.

5. LAMARE, R. de $A$ vida do bebê. 28 ed., Rio de Janeiro: Block, p. 164 - 6.

6. MANUAL de Organização e procedimentos do CTI neonatal do Hospital Golden Garden, Gonden Cross. Brasilia, 1987. p. 60.
7. MARCONDES, E.Pediatria básica. 7 ed., São Paulo: Sarvier. 1986. p. 1497. v. 2.

8. MINIS TÉRIO DA SAÚDE. Secretaria de Assistência Médica. Creches: instruçōes ! I a instalação e funcionamento. RJ, 1972. p. 11.

9. MURAHOVSCHI, J. Pediatria: diagnóstico e tratomento. 4 ed., São Paulo: Savier, 1987. p. 615-6.

10 SAMPAIO, V.R.C. Creche: atividades desenvolvidas com a criança. Rio de Janeiro: EBM, 1984. p. 69.

11. SCHUWAR TSMANN, E. Medicamentos em pediatria. 3 ed., São Paulo: Savier, 1986. p. 100-103.

12. WAECH TER, E.H. Enfermagem pediatrica. 3 ed., Rio de Janeiro: Interamericana, 1976. p. 289.

13. WERNER, D. Onde não hámédico. 8 ed., Sảo Paulo: Paulinas / Tapes, 1985. p. 215. 